\title{
O papel do comentário escrito no método da instrução ao sósia e seu uso na formação de professores
}

\author{
Eliane Gouvea Lousada* \\ Flavia Fazion**
}

\begin{abstract}
Resumo
Este artigo tem por objetivo discutir o papel do comentário escrito no método da instrução ao sósia (IS) e seu uso na formação de professores, além de propor uma reflexão sobre o interesse em estudar a função epistêmica (SCHNEUWLY, 2008; BLASER; LAMPRON; SIMARD-DUPUIS, 2015) da escrita como auxiliar do método da IS. Para tanto, analisamos os comentários escritos redigidos por professores que assistiram a um curso de pós-graduação sobre o trabalho docente e que vivenciaram o método da IS como uma maneira de ligar os saberes teóricos do curso à sua aplicação prática. Para atingir nossos objetivos, apoiamo-nos nos pressupostos teóricos e metodológicos da Clínica da Atividade e Ergonomia da Atividade (CLOT, 1999; AMIGUES, 2004; SAUJAT, 2010; FAÏTA, 2004), acrescidos de conceitos do interacionismo sociodiscursivo (BRONCKART, 1999; 2008) para a compreensão do agir linguageiro expresso nos textos produzidos pelos participantes. Na análise dos dados, percebemos que o professor, ao escrever o texto comentário enquanto escuta a IS, torna-se um outro para si mesmo, observando sua prática de um outro ponto de vista. Alguns índices linguísticos e os sentidos dos conteúdos enunciados permitem identificar esses momentos e, assim, contribuem para mostrar a função epistêmica da escrita no conhecimento de si como professor e de sua prática.
\end{abstract}

Palavras-chave: Formação de professores. Instrução ao sósia (IS). Comentário escrito. Função epistêmica da escrita.

\section{Le rôle du commentaire écrit dans la méthode de l'instruction au sosie et son utilisation dans la formation des enseignants}

\section{Résumé}

L'objectif de cet article est de discuter le rôle du commentaire écrit dans la méthode de l'instruction au sosie (IS) et de son utilisation dans la formation des enseignants, ainsi que de proposer une réflexion sur l'intérêt à étudier la fonction épistémique (SCHNEUWLY, 2008; BLASER; LAMPRON; SIMARD-DUPUIS, 2015) de l'écriture en tant qu'appui à la méthode de l'instruction au sosie. Pour ce faire, nous avons analysé les commentaires écrits rédigés par des enseignants ayant suivi un cours de troisième cycle sur le travail d'enseignement et ayant expérimenté la méthode de l'IS comme moyen de relier les connaissances théoriques du cours à leur application pratique. Pour atteindre nos objectifs, nous nous sommes appuyées sur le cadre théorique et méthodologique de la Clinique de l'activité et de l'Ergonomie de l'activité (CLOT, 1999; AMIGUES, 2004; SAUJAT, 2010; FAÏTA, 2004), ainsi que sur les concepts de l'Interactionnisme socio-discursif (BRONCKART, 1999; 2008) pour la compréhension de l'agir langagier exprimé dans les textes produits par les participants. En analysant les données, nous avons constaté que l'enseignant, en écrivant le commentaire lors de l'écoute des instructions du sosie, devient un autre pour lui-même, observant sa pratique d'un autre point de vue. Certains indices linguistiques et la signification des contenus énoncés permettent d'identifier ces moments et contribuent ainsi à montrer la fonction épistémique de l'écriture dans la connaissance de soi en tant qu'enseignant et de sa pratique.

Recebido: 20/03/2019

Aceito: 19/07/2019

\footnotetext{
* Faculdade de Filosofia, Letras e Ciências Humanas da Universidade de São Paulo (FFLCH-USP). Mestre e Doutora em Linguística Aplicada e Estudos da Linguagem pela Pontifícia Universidade Católica de São Paulo.

** Universidade de São Paulo (USP). Doutora em Letras pela Faculdade de Filosofia, Letras e Ciências Humanas da USP. Pós-doutoranda no Programa Estudos Linguísticos, Literários e Tradutológicos em Francês da Faculdade de Filosofia, Letras e Ciências Humanas da USP (2018).
} 


\section{Introdução}

Inúmeras das linhas teóricas que embasam o campo da formação docente têm se baseado no potencial das verbalizações sobre a atividade de trabalho dos professores como uma maneira de conscientizálos sobre suas ações e contribuir para sua formação. É o caso dos trabalhos sobre o professor reflexivo, iniciados por Schön $(1995 ;$ 2000) e seguidos por vários outros pesquisadores (ZEICHNER, 1993; LIBERALI, 1996), dos estudos sobre as narrativas de vida (CONNELLY; CLANDININ, 1995) e de tantos outros trabalhos com inspirações diversas. Nessa vertente, embora com objetivos, inspirações e pressupostos teórico-metodológicos bastante diversos, mais recentemente, encontramos os estudos que partem do vasto campo das Ciências do Trabalho (SOUZA-E-SILVA; FAÏTA, 2002), que propõem o uso de diversos tipos de verbalizações sobre o trabalho aplicados à formação docente (MACHADO, 2004; LOUSADA, 2006; MACHADO; LOUSADA; FERREIRA, 2011). Essas pesquisas partem do princípio de que a linguagem tem o poder de reconstruir as atividades vividas, por si ou por outros, no trabalho e sobre o trabalho docente, com o intuito de trazê-las para o plano consciente, buscando a transformação da ação. $\mathrm{O}$ estudo que apresentaremos neste artigo inscreve-se nessa corrente ao propor uma análise das verbalizações de professores sobre seu trabalho, procurando contribuir para a sua formação, partindo de pressupostos teórico-metodológicos propostos por algumas das vertentes que estudam o trabalho, tais como a Clínica da Atividade (CLOT, 1999; 2001a; 2010) e a Ergonomia da Atividade dos Profissionais da Educação (AMIGUES, 2002; 2004; SAUJAT, 2004; 2010).

Os dados que analisaremos provêm de um curso de pós-graduação intitulado "Analisar o trabalho educacional: uma abordagem a serviço do métier", que teve por objetivo discutir o papel de algumas das vertentes das Ciências do Trabalho para a formação de professores. Com base nos estudos vygotskianos (1934/1997, 1925/2004) que ressaltam a importância da prática para a aprendizagem, o curso procurou colocar os pós-graduandos em situações em que tivessem que verbalizar sobre o trabalho, para que pudessem, de fato, experenciar os métodos propostos pela Clínica da Atividade e Ergonomia da Atividade. Dessa forma, os mestrandos e doutorandos não apenas estudaram do ponto de vista teórico os conceitos que embasam essas vertentes, mas também utilizaram alguns desses métodos para produzirem verbalizações sobre o seu trabalho. De forma específica, esses alunos vivenciaram o método da IS, proposto por Oddone e outros na década de 70 (ODDONE et al., 1981) e retomado por Clot (2001b) a partir dos pressupostos da Clínica da Atividade. O método da IS prevê a criação de uma situação hipotética na qual o trabalhador é um "instrutor" que conta para um "sósia" sua jornada de trabalho, com o objetivo de que o trabalhador verbalize sobre seu trabalho. Reconstruído por Clot (2001b), o método prevê que se criem pequenos grupos de trabalhadores nos quais um deles é o instrutor e os outros são os sósias. Em um primeiro momento, trata-se de fazer a instrução e debater com os colegas sobre o trabalho. Em um segundo momento, a instrução e o debate, que foram gravados em áudio, são objeto de comentários escritos pelos participantes. Em um terceiro momento, os pequenos grupos se reúnem novamente para que os textos escritos sejam lidos e discutidos.

Neste artigo, são os comentários escritos pelos professores sobre o áudio gravado durante a IS que constituem nossos dados de análise. Nosso objetivo é justamente o de discutir o papel do comentário escrito no método da IS e seu uso na formação de professores. Essa escolha se justifica pelo fato de não haver muitos estudos sobre o papel desses comentários escritos na IS e também pelo interesse em estudar a função epistêmica (SCHNEUWLY, 2008; BLASER; LAMPRON; SIMARD-DUPUIS, 2015) da escrita como auxiliar do método da IS. Para tanto, apresentaremos uma análise dos textoscomentários escritos como uma das etapas do método da IS, aplicado no curso de pós-graduação, com o objetivo de criar um distanciamento em relação à prática docente que poderia contribuir para a reflexão sobre o trabalho de ensinar e que, nesse sentido, poderia ser um instrumento útil na formação 
de professores. O objetivo específico é mostrar que a escrita, quando usada no âmbito da formação de professores e, sobretudo, quando é associada a métodos que valorizam a dimensão social da atividade de trabalho, pode ser um instrumento importante para criar um distanciamento de si que permite refletir sobre as ações.

Para atingir nossos objetivos, apoiamo-nos nos mesmos pressupostos teóricos e metodológicos da Clínica da Atividade e Ergonomia da Atividade (CLOT, 1999; 2001a; 2010; AMIGUES, 2002; 2004; SAUJAT, 2004; 2010; FAÏTA, 2002; 2004), acrescidos de conceitos do interacionismo sociodiscursivo (BRONCKART, 1999; 2006; 2008) para a compreensão do agir linguageiro expresso nos textos produzidos pelos participantes, por meio do modelo de análise de textos. Nosso estudo faz parte das pesquisas desenvolvidas pelo Grupo ALTER-CNPq e ALTER-AGE-CNPq (LOUSADA, 2006; 2017; BUENO, 2007; DANTAS-LONGHI, 2017; MENEZES, 2015; SOARES, 2016; FAZION, 2016) no que diz respeito ao papel dos textos (orais ou escritos) para a formação de professores e, sobretudo, quanto ao papel da linguagem nos dispositivos de "análise das práticas" (BULEA; BRONCKART, 2010; YVON; SAUSSEZ, 2010) que contribuem para a formação de professores. Ele se diferencia de outras pesquisas que utilizam textos orais ou escritos com o objetivo de formação, pois considera o papel do coletivo e seu potencial no desenvolvimento dos professores; preocupa-se em dar voz aos professores em lugar de levá-los a pensar de uma determinada maneira; procura fazer com que a experiência vivida por cada um deles e pelos pares possa se tornar uma maneira de viver outras experiências (CLOT, 1999; 2001a).

\section{Quadro teórico-metodológico}

Há muito tempo duas preocupações têm acompanhado o homem: melhorar a eficiência do trabalho humano por um lado e, por outro, diminuir seu sofrimento no trabalho e prevenir riscos à saúde (LAVILLE, 2007). Nesse caminho surge, na década de 60, um projeto de ergonomia francófona cuja especificidade é a análise da atividade estudada em situação de trabalho. Dentre as várias correntes das chamadas Ciências do Trabalho que surgiram desde então, baseamo-nos na Clínica da Atividade (CLOT, 1999; 2001a), que tem por objetivo transformar as situações de trabalho, ampliando o poder de agir do trabalhador, e na Ergonomia da Atividade (FAÏTA, 2004; AMIGUES, 2004; SAUJAT, 2004), que tem por objetivo compreender a situação de trabalho docente, levando em conta todos os participantes envolvidos, e procura compreender os conflitos nessa situação de trabalho.

Para a ergonomia francófona clássica, no estudo sobre o trabalho humano, um dos conceitos principais é a distância entre a tarefa, que é o que deve ser feito (trabalho prescrito), e a atividade, o que se faz (intitulado trabalho real). Essa distância é natural e inevitável: para os ergonomistas, o trabalho real nunca é igual ao prescrito (GUÉRIN et al., 2001).

Nesse quadro, surgem outras pesquisas, como, por exemplo, na vertente da Psicologia do Trabalho, os estudos de Clot (1999; 2001a). Para esse autor (CLOT, 1999; 2001a), o querido, o possível e o impossível fazem, tanto um como outro, parte do real do trabalho. Baseando-se nos estudos de Vygotski (1934/1997), para o qual o homem está cheio, a cada instante, de possibilidades de ação ainda que apenas uma se realize - Clot (2001a) propõe a noção de "real da atividade". De acordo com ele (CLOT, 2001a, p. 125), "o que se faz — e que podemos considerar como atividade realizada — é somente a atualização de uma das atividades realizáveis na situação na qual acontece" ${ }^{1} \mathrm{O}$ autor explica que a distinção e as relações entre atividade realizada e real da atividade explicam o fato de a Clínica da Atividade se preocupar em realizar um estudo minucioso do que é feito pelos trabalhadores,

1 Tradução nossa, com base no original: "Ce qui se fait — et que l'on peut considérer comme l'activité réalisée — n'est jamais que l'actualisation d'une des activités réalisables dans la situation où elle voit le jour." 
com o interesse de lhes oferecer a possibilidade de um retorno ao real a partir do estranhamento sobre uma atividade realizada (CLOT, 2001a). Nessa perspectiva, Clot (1999; 2001a) propõe o termo "trabalho realizado", já que o termo "real", para ele, designa outro conceito, o de real da atividade.

Os estudos da Clínica da Atividade vão se concentrar, assim, em desenvolver métodos para reconstruir a experiência vivida, fazendo com que o "real da atividade", que não pode ser apreendido na ação que se concretizou, já que muitas ações foram impedidas ou amputadas, possa emergir. Dessa forma, partindo do princípio vygotskiano de que a experiência vivida somente é acessível por meio de traços que precisam ser reconstruídos com a ajuda de métodos indiretos (VYGOTSKI, 1934/1997; 1925/2004), ou seja, que propõem organizar um redobramento da experiência vivida, alguns pesquisadores (CLOT, 2001a; FAÏTA; VIEIRA, 2003) propuseram métodos "indiretos" de intervenção nas situações de trabalho que visam a criar uma relação mediada do sujeito com sua atividade de trabalho por meio de verbalizações sobre a atividade. Por meio das verbalizações, a atividade é recriada, revivida em um outro contexto, permitindo que o indivíduo se torne um outro para si mesmo. É uma maneira de fazer emergir o real da atividade e fazer com que os trabalhadores ampliem seu poder de agir em relação a essas situações.

Um dos métodos que nos interessa particularmente neste estudo é a IS. Desenvolvido por Ivar Oddone no final dos anos 70, na Fiat, no contexto dos seminários de formação operária da Universidade de Torino (ODDONE et al., 1981), o método foi adaptado por Clot (1999), no intuito de transformar as situações de trabalho. O "exercício" da IS implica um trabalho do coletivo do qual um voluntário recebe a seguinte instrução: "Suponha que sou seu sósia e que terei que te substituir em seu trabalho. Quais instruções você me daria para que ninguém percebesse essa substituição?”. A partir dessa instrução, o instrutor-trabalhador passa a contar para o sósia-interveniente todos os procedimentos necessários para a sua hipotética substituição. A instrução é gravada em áudio e, em seguida, em sua casa, o instrutor-trabalhador retoma os áudios, escolhe trechos para transcrever e produzir comentários por escrito. Após a produção dos comentários escritos, o grupo inicial se reúne novamente em um "retorno ao coletivo" em que cada instrutor traz os comentários escritos para debate. De acordo com Clot (2001b), esse procedimento possibilita a confrontação do sujeito consigo mesmo e com sua atividade em dois tempos. Em uma primeira fase, o sujeito se confronta consigo mesmo pela mediação da atividade do sósia. Na segunda, ele se confronta com os traços materializados na gravação da atividade de instrução, mediado por uma atividade de escrita que pode ser dirigida tanto ao sósia quanto ao grupo (CLOT, 2001b; SAUJAT, 2002). A atividade de escrita pode, então, tornarse ponto de partida para uma outra história, já que o distanciamento possibilitado pela escrita pode fazer com que a experiência vivida, projetada na IS e revivida na leitura do comentário escrito, se torne a experiência de outro.

No campo da formação docente, o método da IS tem sido utilizado tanto para professores iniciantes (SAUJAT, 2004; SOARES, 2016) quanto mais experientes (MENEZES, 2015). Como aponta Saujat (2004, p. 6), ao procurar fazer com que o sósia aja de determinada forma para que ele realmente possa fazer a substituição, o professor iniciante descobre coisas novas em si mesmo. Trata-se de uma forma de perceber, por intermédio da atividade endereçada ao sósia, as escolhas que foram feitas e as que poderiam ter sido feitas, em outras palavras, o real da atividade. Para citar Clot (2001b, p. 9), ao se transformar em linguagem, as atividades se reorganizam e se modificam. ${ }^{2}$ Nesse sentido, em seu primeiro momento, o método da IS permite o confronto com a própria atividade, sua reorganização pela linguagem, um distanciamento e a adoção de um outro ponto de vista em relação à atividade projetada e, em consequência, uma tomada de consciência que pode contribuir para sua modificação futura, ou, ao menos, a modificação da relação do sujeito com sua atividade.

2 "En se transformant en langage les activités se réorganisent et se modifient." (CLOT, 2001b). 
Em seu segundo momento, em que o professor redige um comentário escrito sobre a própria atividade, o método da IS permite um outro distanciamento propiciado pela atividade de escrita. Na esteira de Saussez e Yvon (2014), podemos interpretar o papel da escrita da mesma forma que propõe Schneuwly (2008), ao desenvolver a ideia de que a relação com a escrita, quando a criança inicia sua aprendizagem na escola, permite ter acesso reflexivamente aos processos de controle de suas intenções e da forma de executá-las, em outras palavras, de controle de si. Schneuwly (2008, p. 113) afirma, também, que as unidades linguísticas mobilizadas na escrita contribuem para instaurar uma relação de distanciamento do texto, que demanda uma atitude voluntária e consciente. Para Chartrand, Blaser, Gagnon (2006, p. 277), a escrita solicita instâncias psicológicas de controle e de gestão da produção linguageira que são mais complexas do que no oral, já que as exigências formais da escrita demandam uma maior abstração. Durante a escrita, o sujeito se vê privado das interações e tem que organizar sozinho sua produção linguageira, o que demanda um trabalho cognitivo mais complexo (CHARTRAND; BLASER; GAGNON, 2006, p. 277).

Embora, em nosso caso, diferentemente do que relata Schneuwly (2008), trate-se de adultos que já dominam a atividade de escrita, levantamos a hipótese de que a mediação da escrita, por meio do texto-comentário redigido ao escutar sua instrução endereçada ao sósia, engaje o professor em formação em uma atividade heurística de descoberta e de tomada de consciência (ou de vivência de "estranhamentos") em relação à sua prática. E, justamente, pelo fato de que a IS permite um terceiro momento, de debate com os pares do grupo inicial, ou seja, o "retorno ao coletivo", sobre os estranhamentos causados pela escuta da IS e pelo comentário escrito, parece-nos que esse método é profícuo na formação de professores.

Antes de avançarmos para os aspectos contextuais, metodológicos e para as análises dos comentários escritos sobre a IS, parece-nos importante tecer dois comentários. O primeiro diz respeito ao método da IS como parte dos dispositivos de "análise das práticas" frequentes, há algumas décadas, na formação de professores em países francófonos. O segundo traz a questão do aspecto inovador da análise dos comentários escritos da IS.

Bulea e Bronckart (2010, p. 44) mencionam o fato de que, na atualidade, dois tipos de "engenharia didática" estão presentes na formação de professores. O primeiro é a já conhecida formação por transmissão de saberes, bastante corrente, a nosso ver, nos cursos de formação de professores no Brasil, quer seja em ambiente universitário (licenciatura) ou não. Ele ocorre, sobretudo, por meio de aulas, nas quais os conteúdos da Didática e da Pedagogia são transmitidos. O segundo, oriundo das Ciências do Trabalho, tem sido organizado a partir de dispositivos de análise das práticas, nos quais os (futuros) professores são confrontados, por meio de vídeos, áudios ou transcrições, a situações em que é possível ver o trabalho realizado por outros professores, ou o seu próprio trabalho. Para Bulea e Bronckart (2010, p. 44), esse dispositivo conduz a tomadas de consciência ou a relações de inteligibilidade de certas características do trabalho docente. No curso de pós-graduação cujos dados analisamos neste artigo, a preocupação era a de mostrar aos professores e pós-graduandos que o trabalho do professor podia ser considerado a partir de uma outra perspectiva, a do ensino como trabalho, e que, para tanto, os métodos da autoconfrontação (FAÏTA; VIEIRA, 2003) e IS podem ser utilizados. Dessa forma, os professores e pós-graduandos foram expostos a um dispositivo de análise das práticas, seja da prática de outros, quando analisamos autoconfrontações e instruções ao sósia vividas por outros, ou, ainda, pela IS vivenciada por eles próprios, na atividade executada em aula.

No caso da IS, como apontam Bulea e Bronckart (2010, p. 52), a atividade de trabalho é projetada em seus mínimos detalhes, abordando os modos de comportamento, as relações com os colegas e com a hierarquia, entre outros. A partir de uma "planificação" de um de seus momentos correntes de trabalho que ele tem que indicar a um substituto fictício, o professor toma consciência das propriedades efetivas ou possíveis de sua atividade de trabalho. 
Nesse sentido, dando continuidade ao que propõem Bulea e Bronckart (2010), podemos considerar a IS no quadro dos dispositivos de análises das práticas nos quais os futuros professores são confrontados a suas situações reais de trabalho, à verbalização sobre a atividade, seja por escrito ou oralmente (BULEA; BRONCKART, 2010). Para Yvon e Saussez (2010, p. 211), a IS, ainda que proposta no quadro da psicologia do trabalho, pode fazer parte do dispositivo de análise das práticas de forma original, já que a atividade de trabalho visada é a cotidiana, em seu caráter trivial. Para eles (YVON; SAUSSEZ, 2010), a análise das práticas está normalmente centrada na transformação dos sujeitos por meio da análise do que é feito, e é por meio da linguagem que a atividade é identificada e interpretada. Trata-se, segundo esses autores, de um projeto de autoconhecimento (YVON; SAUSSEZ, 2010), que, geralmente, se organiza em três fases: uma fase descritiva, uma fase de questionamento e uma fase de interpretação (YVON; SAUSSEZ, 2010, p. 208). Ao analisar o que é feito em sua atividade profissional, a análise das práticas pode ser um instrumento de profissionalização, voltado para o indivíduo para o qual o grupo, ou seja, a dimensão coletiva, é um recurso (YVON; SAUSSEZ, 2010, p. 211).

Passemos a nosso segundo comentário, que diz respeito à proposta de análise do comentário escrito da IS. Apesar de sua longa história, que data dos anos 70, e dos frequentes usos e adaptações que têm sido feitos do método da IS por pesquisadores da Clínica da Atividade e da Ergonomia da Atividade, poucos são os artigos que abordam o papel do comentário escrito, pois a maioria dos estudos focaliza os efeitos que a própria entrevista de IS causa nos sujeitos, ou seja, a análise das transcrições da IS. Com efeito, as pesquisas desenvolvidas e que já mencionamos (SAUJAT, 2004; CLOT, 2001b; MENEZES, 2015; SOARES, 2016) propuseram uma análise e interpretação das transcrições das entrevistas de IS. A nosso ver, o comentário escrito da IS tem uma função bastante importante e, por isso, deveria ser também objeto de análise. Como dissemos, é o caráter epistêmico da escrita que nos parece importante para a formação de professores. Segundo Blaser, Lampron, Simard-Dupuis (2015, p. 51), o potencial epistêmico da escrita favorece a apropriação do conhecimento e a construção dos saberes, tendo um potencial heurístico, já que propicia a descoberta e a criação. A seguir, veremos o contexto em que as ISs e os comentários escritos foram realizados, para, em seguida, mostrarmos as análises que realizamos dos comentários escritos, ressaltando seu papel para a formação dos pós-graduandos e professores.

\section{Contexto do curso e utilização do método da instrução ao sósia}

Os dados foram coletados em um curso de pós-graduação (Analisar o trabalho educacional: uma abordagem a serviço do métier) ministrado em 2017, do qual participaram 13 alunos, 11 regularmente matriculados e dois ouvintes. Todos os alunos estavam inscritos no mestrado ou no doutorado, mas eram professores, tendo diferentes experiências em ensino, e realizavam pesquisa na área.

O curso teve por objetivo propor uma reflexão sobre a formação para o trabalho de ensino, discutindo como as ferramentas de análise do trabalho, pertencentes ao quadro teórico da ergonomia da atividade, podem contribuir para isso. Ele visou a colocar em discussão a análise da atividade de ensino, a questão dos dilemas do trabalho de ensino, os métodos de compreensão, análise e transformação das situações de trabalho educacional, a transmissão de gestos profissionais, entre outros. Para tanto, o curso tomou por base os pressupostos teóricos e metodológicos da ergonomia da atividade dos profissionais da educação (AMIGUES, 2004; SAUJAT, 2004; FAÏTA, 2004) e da clínica da atividade (CLOT, 1999; 2001a). Em lugar de fornecer exemplos e ensinar modos de fazer 
docentes, o curso buscou discutir o que os professores faziam em suas aulas, procurando colocar em diálogo diferentes maneiras de realizar o trabalho do professor. No curso, os alunos-professores "experimentaram" os métodos para melhor se apropriarem deles.

O curso contou com seis aulas de quatro horas, que combinaram formação teórica e prática. A parte prática consistiu na exposição dos pós-graduandos e professores dos métodos chamados indiretos, tais como autoconfrontação e IS, seja vivenciados por eles próprios ou pela observação das atividades de trabalho de outros professores, que era trazida para a aula. Por exemplo, os pós-graduandos e professores puderam ler a transcrição de uma entrevista de IS, discutir sobre o que observaram, antes de vivenciar o método por si mesmos. Tratou-se, assim, de um dispositivo de análise das práticas que foi combinado com a parte teórica característica de um curso de pós-graduação.

Sendo assim, na quarta aula do curso, foi colocado em prática o método da IS. Para tanto, foram formados quatro grupos, três com três participantes e um com quatro. Em cada grupo, foi escolhido um sósia e dois instrutores. No grupo de quatro, foram três instrutores. A recomendação dada foi: pensar em um dia típico e preciso de seu trabalho de professor e dar a instrução como se o sósia fosse substituí-lo naquele dia e com aquele grupo específico. O pós-graduando que assumiu a função de sósia deveria fazer perguntas de esclarecimento, procurando conhecer a atividade de trabalho em seus mínimos detalhes, para assegurar a substituição fictícia. Ele devia centrar suas perguntas no "como" e não no "por que".

Durante a aula, os grupos iniciaram a instrução, da seguinte forma, nos diferentes grupos:

- Instrução do $1^{\circ}$ professor-instrutor, com perguntas de esclarecimento do sósia (10 minutos)

- Instrução do $2^{\circ}$ professor-instrutor, com perguntas de esclarecimento do sósia (10 minutos)

- No grupo de quatro pós-graduandos e professores, instrução do $3^{\circ}$ professor, da mesma forma.

- Debate com os dois professores-instrutores e o sósia: cada professor tinha a oportunidade de discutir a atividade imaginada e relatada do outro (10 minutos).

Em cada grupo, os momentos de instrução e de debate foram gravados em áudio e os arquivos foram distribuídos entre os participantes dos respectivos grupos. Em casa, como tarefa para a aula seguinte, os alunos deveriam escutar o áudio com sua fala, observar os estranhamentos, questões e interpelações, escolhendo trechos e transcrevendo-os. Os trechos escolhidos deveriam constituir objeto de um comentário escrito e seriam trazidos para a discussão na aula seguinte.

Uma semana depois, fizemos o "retorno ao coletivo", em que os mesmos grupos foram formados e o procedimento foi o seguinte:

- Leitura do $1^{\circ}$ professor de seus comentários escritos sobre o trecho que causou estranhamento, interpelações, quando escutou a IS em casa.

- Todos no grupo fazem perguntas/comentários sobre o que ouviram (10 minutos).

- Perguntas do sósia (5 minutos).

- Leitura do $2^{\circ}$ professor de seus comentários escritos sobre o trecho que causou estranhamento, interpelações, quando escutou a IS em casa.

- Todos no grupo fazem perguntas/comentários sobre o que ouviram (10 minutos).

- Perguntas do sósia (5 minutos).

- Repetição do procedimento no grupo de quatro pós-graduandos e professores.

-Discussão, debate com todos os membros do grupo sobre os comentários escritos, os estranhamentos (10 a 15 minutos). 
Esse encontro também foi registrado em áudio, de modo que, no final, contamos com duas gravações em áudio de cada um dos quatro grupos e um total de nove comentários escritos (dois instrutores em cada um dos três grupos de três e três instrutores no grupo de quatro), disponibilizados pelos estudantes-professores que optaram por compartilhar seus textos com a professora-pesquisadora.

\section{Seleção dos dados e procedimentos de análise}

Para este artigo, selecionamos os comentários escritos por dois pós-graduandos-professores que estavam em grupos diferentes e que assumiram o papel de instrutores. Cabe ressaltar que esses dois comentários foram escolhidos, pois, justamente, nestes dois grupos, o método da IS pareceu ter tido maior impacto em sua experiência. Essa afirmação baseia-se em dois elementos: primeiramente, observamos, durante as ISs realizadas na aula, mudanças de atitude e de comportamento que fizeram com que os alunos acabassem comentando-os e verbalizando o impacto do método; em segundo lugar, na aula de encerramento do curso, foi proposta uma discussão sobre o uso dos métodos no curso, e esses dois grupos foram os que mais ressaltaram terem sido "afetados", no sentido de Clot (2015), pelo método.

Dentro desses dois grupos, dois pós-graduandos apresentaram, no trabalho final, excertos de seus comentários escritos e, portanto, são esses os dados que traremos para a análise. A título de ilustração, traremos, também, algumas transcrições de uma IS, quando necessário, para explicar os dados e os conteúdos abordados. Abaixo, um quadro explica os dados que serão objeto de análise, atribuindo siglas ao que será analisado.

\section{Quadro 1}

\begin{tabular}{|l|l|l|l|l|}
\hline \multirow{2}{*}{ Dados coletados } & \multicolumn{2}{|c|}{ Grupo 1 } & \multicolumn{2}{c|}{ Grupo 2 } \\
\cline { 2 - 5 } & Instrutor 1 (I1) & Instrutor 2 (I2) & Instrutor 1 (I1) & Instrutor 2 (I2) \\
\hline $\begin{array}{l}\text { Instrução ao sósia } \\
\text { (IS) - transcrição do } \\
\text { áudio }\end{array}$ & & G1-IS & & \\
\hline $\begin{array}{l}\text { Debate após a IS - } \\
\text { transcrição do áudio }\end{array}$ & & & & \\
\hline $\begin{array}{l}\text { Comentário escrito } \\
\text { sobre a IS ou sobre } \\
\text { o debate }\end{array}$ & & G1-CE & G2-CE & \\
\hline $\begin{array}{l}\text { Retorno ao coletivo } \\
\text { - transcrição do } \\
\text { áudio }\end{array}$ & & & & \\
\hline
\end{tabular}

Fonte: Dados coletados por uma das autoras.

Para analisar os dados, baseamo-nos em algumas categorias de análise do interacionismo sociodiscursivo (BRONCKART, 1999). Primeiramente, procuramos discutir o contexto de produção físico e sociossubjetivo das entrevistas de IS e dos comentários escritos. Em seguida, concentramos nossas análises nos mecanismos enunciativos, a terceira camada da arquitetura textual, ou seja, das vozes e modalizações. Para a análise das vozes, baseamo-nos, também, em autores como Maingueneau (2001). De modo específico, procuramos observar as vozes e as modalizações, da seguinte forma: 
- Análise das vozes: identificação dos dêiticos de pessoa empregados e a quem se referiam; sinais gráficos que indicavam presença de outras vozes; mudanças de sentido, deslocamentos na fala da mesma pessoa entre dois momentos diferentes.

- Análise das modalizações: identificação de verbos modais, advérbios, adjetivos que permitiram classificar os complexos modais em lógicos (certeza/incerteza), deônticos (deveres/permissões), apreciativos (julgamentos de valor) e pragmáticos (ações, intenções).

Fizemos, primeiramente, a identificação dos dêiticos de pessoa, sobretudo o uso de "eu" (je) ou "você" (tu, vous), procurando perceber quem enunciava a cada momento. Em seguida, procuramos perceber se, nos momentos de IS e do comentário escrito, os conteúdos veiculados coincidiam ou se havia deslocamentos, mudanças, entre os sentidos, no primeiro e no segundo momentos. Procuramos, também, identificar caracteres gráficos que indicavam inserção de outras vozes, como, por exemplo, no caso de metacomentários em negrito. Em ambos os casos, tanto de deslocamentos e mudanças de sentidos quanto nos metacomentários, consideramos que se tratava de outra voz que aparecia no momento da redação do texto escrito, que, embora se tratando da mesma pessoa física, no plano sociossubjetivo, já não se tratava do mesmo enunciador. Identificamos, assim, uma distância entre o enunciador da IS e o enunciador do comentário escrito, possibilitada pelo distanciamento no tempo, mas, sobretudo, pela própria atividade de escrita.

A análise das modalizações procurou dar apoio às outras análises, possibilitando chegar a nuances interpretativas sobre o papel dos comentários escritos no método da IS.

\section{0 que revelam os comentários escritos no método da instrução ao sósia}

Antes de passarmos para as análises propriamente ditas dos comentários escritos, cabe tecer algumas considerações sobre o contexto em que as ISs e os textos comentários foram produzidos. Tratou-se, como dissemos, de um curso de pós-graduação em que os alunos eram todos professores e realizavam pesquisa na área. Eles haviam lido sobre o método da IS e outros métodos indiretos antes de vivenciá-los no curso. Por um lado, tratou-se de um "exercício", o que talvez explique o fato de que dois grupos não tiveram os mesmos benefícios da vivência do método. Por outro lado, nos grupos que escolhemos para a análise, o método alcançou seu potencial, provavelmente por ter sido realizado dentro de um projeto que os pós-graduandos encararam como contribuindo para seu próprio autoconhecimento. Um dos fatores que contribuiu para isso foi o fato de que não havia nota nem obrigação de realizar a experiência com o método da IS.

No momento da IS, os pós-graduandos dirigiam-se a seu pequeno grupo de dois ou três colegas de profissão e de mestrado/doutorado. O professor da disciplina não representava um destinatário em si, pois, embora pudesse escutar as ISs, sabia-se que apenas alguns trechos seriam objeto de discussão na aula. Quanto ao comentário escrito, os pós-graduandos sabiam que os destinatários seriam seus colegas no pequeno grupo de três ou quatro e, de maneira incidental, o professor da disciplina e os participantes dos outros grupos.

Também sobre o contexto de produção, parece-nos importante destacar que houve três momentos de produção: o da IS, o do comentário escrito e o do retorno ao coletivo. Para efeitos de análise, consideramos que se tratava, em cada momento, do mesmo emissor, a mesma pessoa física, no entanto, eram enunciadores "diferentes", pois já não tinham a mesma relação com o que estava sendo ou havia sido dito.

No excerto que analisaremos a seguir, apresentamos três momentos de distanciamento proporcionados pela IS realizada durante o curso de pós-graduação. Os pós-graduandos e professores 
realizaram a transcrição de trechos de sua instrução e produziram o comentário por escrito para o retorno ao coletivo. Observamos, assim, um primeiro momento de distanciamento da atividade durante a instrução. Esse distanciamento é marcado pelo uso do "você", uma vez que, para instruir o sósia, há o deslocamento de sua atividade da primeira para a segunda pessoa. Ele é importante para que o instrutor-professor possa ver sua atividade a partir do ponto de vista do outro:

Exemplo 1: "Você vai interfonar, de preferência chega 5 minutos antes, e aí você vai subir. Chegando no apartamento dela, você brinca um pouco com o cachorro dela, que é um cachorro muito fofo e que late muito. Se você não brincar, você não vai conseguir dar aula." (G1 - I1 - instrução ao sósia).

No entanto, como em outras situações de uso do método da IS, muitas vezes o instrutor tem dificuldade para "sair de si", usando "você", e acaba usando "eu". Essa dificuldade pode ser observada abaixo:

Exemplo 2: "Use muito a lousa. Eu te reco... ...É, você deve usar a lousa é... a lousa é grande, então você vai usar sempre que der... você conjuga verbo. Atividade de exercício você também deve colocar sempre as respostas." (G1 - I1 - instrução ao sósia).

Esses lapsos ocorreram mais de uma vez, mas não chegaram a comprometer o método da IS, ao contrário, foram objeto de discussões posteriores sobre a dificuldade de sair de si, deslocando sua atividade e vendo-a como a atividade do outro.

O segundo momento de distanciamento se dá quando o estudante escuta a instrução gravada, em sua casa, seleciona e transcreve trechos que julgou importantes, realizando em seguida um comentário escrito sobre eles. Nos comentários escritos, é comum o uso de "eu", o que se explica por se tratar de outro momento. O fato de que o comentário escrito se distancia no tempo do momento da IS nos ajuda a compreender os papéis que o uso do "você" ou o distanciamento pelo tempo podem ter no processo de reflexão sobre a sua própria atividade de trabalho:

Exemplo 3: "e o que me chamou a atenção também na minha fala daí no geral é que às vezes parece que eu sou tão ++ assertiva." (G2 - I1- comentário escrito). ${ }^{3}$

O terceiro momento de distanciamento acontece durante o retorno ao coletivo, quando o pósgraduando-professor faz a leitura dos trechos que selecionou e dos comentários escritos. Como dissemos, nossas análises incidem sobre os comentários escritos pelos pós-graduandos-professores ao escutarem a IS.

Mas voltemos aos dados trazidos para a análise, os comentários escritos pelos pós-graduandosprofessores. A transcrição foi realizada por um dos pós-graduandos-professores, aqui autodenominado Instrutor 2 - I2. O outro pós-graduando-professor foi identificado como Instrutor 1 - I1, e o sósia - S. Ao transcrever os trechos considerados pertinentes para o retorno ao coletivo, I 2 transcreve, além de suas falas, as falas de I1. Observamos que, além de se confrontar com os traços de sua verbalização, o estudante trouxe a verbalização do outro instrutor como um apoio ao movimento do sentido da atividade para si (SAUJAT, 2002). Esse movimento vai se seguir durante a transcrição dos debates, na qual o estudante introduz comentários, em letras menores e destacados em negrito do texto da transcrição, como um prolongamento de sua reflexão sobre a atividade traduzido pela linguagem escrita na forma de comentar. Vemos um exemplo no excerto abaixo:

I2: ...Então... ...eu ainda tenho dúvidas de como proceder... então eu poderia te dizer o seguinte é... corrige... Geralmente, às vezes, eu passo quatro (4) ou cinco (5) exercícios, e às vezes eu corrijo um (1) ou dois (2)... eu não consigo corrigir tudo e... bom... é isso...

3 Os sinais ++ indicam pausa média. 
Eu corrijo às vezes... Eu corrijo tudo, às vezes eu não corrijo. (IS-I2) (dilema).” (G1 - CE sobre a IS).

O pós-graduando-professor, ao transcrever sua IS, mostra um indício de distanciamento da própria prática ao escolher um termo que tinha sido abordado na parte teórica do curso de pós-graduação (dilema), para qualificar a sua dificuldade em saber como proceder na correção de exercícios. $\mathrm{O}$ pós-graduando, ao escutar o áudio da IS, observa, muito provavelmente, a quantidade de uso de expressões de frequência variadas (às vezes - utilizado 4 vezes, geralmente) e a expressão "ainda tenho dúvidas" para estabelecer uma ligação com os conceitos teóricos que estava estudando no curso, o que lhe permitiu qualificar a questão da correção de exercícios como um dilema em sua prática. Aqui, observamos o potencial da escrita, primeiramente da transcrição da IS, para permitir a descoberta e a reflexão sobre como qualificar a dificuldade. É novamente a escrita que possibilita registrar como ele interpretou aquele momento, permitindo que fosse discutido posteriormente, durante o retorno ao coletivo.

Analisando do ponto de vista linguístico-discursivo, observamos que há duas vozes sobrepostas: I2 no momento da IS; I2' no momento da transcrição da IS. O fato de que I2 pode qualificar sua própria fala no momento da IS de dilema mostra que ele já desenvolveu outro ponto de vista em relação à sua ação, já não se trata mais de I2 e, sim, de I2', ou seja, a escrita permitiu uma atividade heurística de descoberta, tomada de consciência e reflexão sobre palavras para qualificar sua ação.

O excerto abaixo traz a transcrição do áudio do debate logo após a IS. No debate, as diferentes posturas dos dois pós-graduandos-professores quanto ao uso do quadro ficam evidentes e levam I2 a se questionar sobre esse uso. I1, pelo que podemos inferir, utiliza muito pouco o quadro, enquanto I2, autor da transcrição, o utiliza muito. Como no exemplo anterior, os comentários estão destacados do texto da transcrição em negrito e entre parênteses. Vejamos a transcrição e os comentários que aparecem desta vez antes mesmo da própria transcrição do debate:

(Tomada de consciência do uso excessivo do quadro e sua relação com o tempo gasto em sala de aula)

I2: "Eu sou o oposto, eu sou uma pessoa muito dependente de quadro. Se eu não tiver um quadro, uma lousa, pincel colorido, principalmente, eu não consigo trabalhar, é... é uma dependência minha como professora. Eu sinto necessidade de escrever. Até acho que escrevo muito...

$[\ldots]$

O quadro é grande eu encho ele inteiro. Eu escrevo muito... Eu acho que eu precisaria pensar uma outra forma de usar o quadro. Eu perco tempo também escrevendo."

(Tomada de consciência em relação ao método - metodologia de dar aulas, de usar o quadro) (repensar o método de dar aulas e de usar o quadro). (G1 - CE sobre o debate).

No excerto acima, I2 parte de suas observações sobre o uso que faz do quadro (em itálico: dependente do quadro, não consigo trabalhar, dependência, necessidade de escrever, escrevo muito) para qualificar o momento de "tomada de consciência", conceito que tinha visto na parte teórica do curso de pós-graduação. Em seu comentário escrito, vemos que ele qualifica duas vezes seus comentários como sendo uma tomada de consciência, primeiramente em relação ao uso excessivo e ao tempo gasto e, no segundo momento, em relação à própria maneira (método, metodologia, segundo ele) de dar aulas. Observamos, também, que a última frase em negrito e entre parênteses é bastante interessante, pois ela representa um conselho que $\mathrm{I} 2$ dá a si mesmo quanto à sua maneira de ensinar: "repensar", no infinitivo, tem um valor injuntivo, de modalização deôntica, como se ele dissesse: “é 
preciso" repensar a maneira de dar aulas e de usar o quadro.

Também vemos, aqui, a função da escrita, por meio de metacomentários, como uma maneira de se distanciar da ação concreta, permitindo a reflexão e a adoção de posturas diferentes em relação à sua prática.

Utilizando o mesmo tipo de análise linguístico-discursivo, observamos novamente que há duas vozes sobrepostas: I2 no momento da IS; I2' no momento da transcrição da IS. O fato de que I2 pode qualificar sua própria fala no momento da IS de "tomada de consciência" mostra que ele já se distanciou de sua ação, tornou-se um outro para si, já não se trata mais de I2 e, sim, de I2', ou seja, a escrita permitiu uma atividade de reflexão sobre sua ação que poderá ser o início de uma mudança, ainda mais pelo fato de que o pós-graduando-professor utiliza a linguagem, nesse segundo momento, para dar indicações para si mesmo. Retomando Schneuwly (2008), podemos observar que a linguagem permite ter acesso aos processos de controle de intenções e da forma de executá-las, ou seja, de controle de si.

O excerto abaixo diz respeito ao Grupo 2, em que um dos pós-graduandos-professores estranha o fato de que, na IS, ele pareceu ter certeza dos procedimentos que instruiu o sósia a fazer, enquanto que ele próprio não tem tanta certeza sobre suas ações:

I1': "E o que me chamou a atenção também na minha fala daí no geral é que às vezes parece que eu sou tão ++ assertiva pra falar assim o que deve o que a sósia deveria fazer sendo que muitas vezes eu fico tão em dúvida da ação que eu devo fazer ou não $+{ }^{4}$ eu não sei esse tom de de de tipo de certeza que eu expressei na hora da fala às vezes não corresponde à minha prática porque eu fico + bom mas pera aí + vou escolher essa atividade mas e se não der certo e se né a gente pensa em tanta coisa antes e quando eu fui descrevendo ++ pra sósia todas as minhas ações é como se não tivesse essa dúvida .” (G2 - CE sobre a instrução ao sósia).

No excerto acima, ao analisarmos as vozes presentes no comentário escrito, vemos apenas a fala de I1', ou seja, não temos traços do que foi de fato dito na IS, pois já entramos diretamente em contato com o comentário de I1 a partir de um outro ponto de vista, posterior, que permite dizer que se trata, na verdade, de I1'. É a atividade de escrita que permite o distanciamento do momento da IS, fazendo com que o pós-graduando-professor possa perceber que sua instrução soou mais assertiva do que ele acha que deveria ter sido. No momento da escuta da IS e da redação do comentário escrito, I1 percebe que, na verdade, ele tem dúvidas em relação às ações projetadas na IS, mas que essas dúvidas não apareceram no momento da instrução. O uso do verbo "dever" com valor injuntivo, indicando obrigação ou mesmo dúvida (no futuro do pretérito), o emprego do termo "dúvida" (duas vezes) e da expressão de tempo às vezes/muitas vezes (três vezes no comentário) expressam o caráter de incerteza e indagação sobre si. O estranhamento é expresso pela modalização apreciativa "tão assertiva", que indica que ela se percebe de outra forma em um momento posterior à IS.

Nos três excertos que analisamos, podemos observar duas vozes que emanam de dois enunciadores: o pós-graduando-professor no momento da IS e o pós-graduando-professor', que aparece no momento da redação do comentário escrito. Embora se tratando da mesma pessoa física, podemos ver que há uma mudança de percepção em relação a si e a suas ações, que é permitida pelo distanciamento e reflexão proporcionados pela escrita.

\section{Conclusões}

Neste artigo, tínhamos por objetivo discutir o papel do comentário escrito no método da IS e seu uso na formação de professores. Para tanto, analisamos os comentários escritos redigidos por

$4 \mathrm{O}$ sinal + indica pausa curta. 
professores que assistiam a um curso de pós-graduação sobre o trabalho docente e que vivenciaram o método da IS como uma maneira de ligar os saberes teóricos do curso à sua aplicação prática. Tratouse, também, de um projeto de autoconhecimento e de contato com a própria maneira de realizar o trabalho de ensino, pela própria natureza do método (YVON; SAUSSEZ, 2010).

$\mathrm{Na}$ análise dos dados, percebemos que o professor, ao escrever o texto comentário enquanto escuta a IS, torna-se um outro para si mesmo, observando sua prática de um outro ponto de vista. Alguns índices linguísticos e os sentidos dos conteúdos enunciados permitem identificar esses dois momentos e, assim, contribuem para mostrar a função epistêmica da escrita no conhecimento de si como professor e de sua prática.

Com efeito, o fato de falar/escrever sobre si dirigindo seu texto a um outro (no momento da escrita, mas, também, no momento de ler o texto escrito para o coletivo) produz um distanciamento, um desdobramento do sujeito, que faz com que ele se torne um outro para si mesmo. Porém, mais do que um projeto de autoconhecimento que fez com que os pós-graduandos-professores refletissem sobre suas práticas e sobre as práticas de seus colegas, percebemos que a escrita permitiu o acesso a instâncias psicológicas de controle de si, o que levou um dos pós-graduandos a formular um conselho (uma ordem?) a si mesmo, sobre a necessidade de repensar sua maneira de dar aulas. Nos dizeres de Clot (2010), tornar-se um outro para si mesmo e entrar em contato com maneiras de agir de outros pode contribuir para viver novas experiências, ampliando o poder de agir e permitindo fazer diferente da próxima vez.

Nesse sentido, as funções heurística e epistêmica da escrita não podem ser negligenciadas e parecem ter um papel preponderante no método da IS. Podemos até nos indagar se, pelo desdobramento da experiência em momentos diferentes, pelos diversos endereçamentos das ISs e dos comentários escritos e pela função epistêmica solicitada pelos comentários escritos, a IS não seria um método mais completo, que poderia trazer efeitos mais perenes nas mudanças das maneiras de fazer propiciadas pelas diversas formações baseadas na análise das práticas.

\section{Referências}

AMIGUES, R. L'enseignement comme travail. In: BRESSOUX, P. (ed.) Les stratégies d'enseignement en situation d'interaction. Note de synthèse pour Cognitique. Paris: Programme Ecole et Sciences Cognitives, 2002. p. 243-262.

AMIGUES, R. Trabalho do professor e trabalho de ensino. In: MACHADO, A. R. (org.). O ensino como trabalho: uma abordagem discursiva. Londrina: Eduel, 2004. p. 35-54.

BLASER, C.; LAMPRON, R.; SIMARD-DUPUIS, E. Le rapport à l'écrit: un outil au service de la formation des futurs enseignants. Lettrure, Seilles, n. 3, 2015.

BRONCKART, J.-P. Atividades de linguagem, textos e discursos: por um interacionismo sociodiscursivo. 2. ed. São Paulo: EDUC, 1999.

BRONCKART, J.-P. Atividades de linguagem, discurso e desenvolvimento humano. Campinas, SP: Mercado das Letras, 2006. (Coleção Ideias sobre Linguagem).

BRONCKART, J.-P. O agir nos discursos: das concepções teóricas às concepções dos trabalhadores. Campinas, SP: Mercado de Letras, 2008. (Coleção Ideias sobre Linguagem).

BUENO, L. A construção de representações sobre o trabalho docente: o papel do estágio. 2007. 220 f. Tese (Doutorado em Linguística Aplicada e Estudos da linguagem). Pontifícia Universidade Católica de São Paulo, São Paulo, 2007.

BULEA, E.; BRONCKART, J.-P. Les conditions d'exploitation et d'analyse des pratiques pour la 
formation des enseignants. Linguarum Arena, Porto, v. 1, n. 1, p. 43-60, 2010.

CHARTRAND, S.-G.; BLASER, C.; GAGNON, M. Fonction épistémique de l'écrit et genres disciplinaires: enquête dans les classes d'histoire et de sciences du secondaire québécois. Revue Suisse des Sciences de l'Éducation, Fribourg, v. 28, n. 2, p. 275-293, 2006.

CLOT, Y. La fonction psychologique du travail. 2. ed. Paris: Presses Universitaires de France, 1999.

CLOT, Y. (org.). Editorial. Clinique de l'activité et pouvoir d'agir. Education permanente, Paris, n. 146, p. 7-16, 2001a.

CLOT, Y. Méthodologie en clinique de l'activité: l'exemple du sosie. In: DELEFOSSE, M. S.; ROUAN, G. (org.). Les méthodes qualitatives en psychologie. Paris: Dunod, 2001b. p. 125-146.

CLOT, Y. Trabalho e poder de agir. Belo Horizonte: Fabrefactum, 2010.

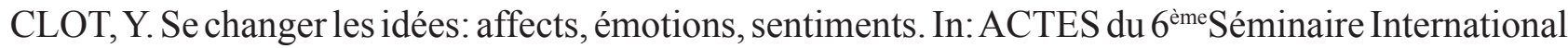
Vygotski. Histoire, Culture, Développement: questions théoriques, recherches empiriques. Paris, jun. 2015.

CONNELLY, M.; CLANDININ, J. Relatos de experiencia e investigación narrativa. In: LARROSA, Jorge. Déjame que te cuente. Barcelona: Editorial Laertes, 1995. p. 11-59.

DANTAS-LONGHI, S. A formação como trabalho: análise da atividade do tuteur-formador de professores de francês como língua estrangeira. 2017.370 f. Tese (Doutorado em Estudos Linguísticos, Literários e Tradutológicos em Francês) - Universidade de São Paulo, São Paulo, 2017.

FAÏTA, D. Análise das práticas linguageiras e situações de trabalho: uma renovação metodológica imposta pelo objeto. In: SOUZA-E-SILVA, M. C. P.; FAÏTA, D. (org.). Linguagem e trabalho: construção de objetos de análise no Brasil e na França. São Paulo: Cortez, 2002. p. 45-60.

FAÏTA, D. Gêneros de discurso, gêneros de atividade, análise da atividade do professor, In: MACHADO, A. R. (org.). O ensino como trabalho: uma abordagem discursiva. Londrina: Eduel, 2004.

FAÏTA, D.; VIEIRA, M. Réflexions méthodologiques sur l'autoconfrontation croisée. Skholê, AixMarseille, hors-série 1, 2003.

FAZION, F. A elaboração de livro didático baseado em gêneros textuais por professores de francês: análise de uma experiência. 2016. 283 f.Tese (Doutorado em Estudos Linguísticos, Literários e Tradutológicos em Francês) - Universidade de São Paulo, São Paulo, 2016.

GUÉRIN, F. et al. Compreender o trabalho para transformá-lo: a prática da ergonomia. São Paulo: Editora Edgard Blücher, 2001.

LAVILLE, A. Referências para uma história da ergonomia francófona. In: FALZON, P. (ed.). Ergonomia. São Paulo: Editora Blucher, 2007. p. 21-32.

LIBERALI, Fernanda Coelho. O desenvolvimento reflexivo do professor. The ESPecialist, São Paulo, v. 17, n. 1, p. 19-37, 1996.

LOUSADA, E. G. Entre o trabalho prescrito e o realizado: um espaço para a emergência do trabalho real do professor. 2006. 333 f. Tese (Doutorado em Linguística Aplicada e Estudos da Linguagem) Pontifícia Universidade Católica de São Paulo, São Paulo, 2006.

LOUSADA, E. G. Intervenção, pesquisa e formação: aprendizagem do trabalho educacional e desenvolvimento de professores. Horizontes, Itatiba, v. 35, n. 3, p. 94-104, set./dez. 2017.

MACHADO, A. R. (org.) O ensino como trabalho: uma abordagem discursiva. Londrina: Eduel, 2004.

MACHADO, A. R.; LOUSADA, E. G.; FERREIRA, A. D. O. O professor e seu trabalho: a linguagem revelando práticas docentes. Campinas: Mercado de Letras, 2011. 
MAINGUENEAU, D. Análise de textos de comunicação. Tradução de Cecília P. de Souza-e-Silva e Décio Rocha. São Paulo: Cortez Editora, 2001.

MENEZES, M. C. O trabalho do professor e as prescrições feitas por órgãos governamentais e estabelecimentos de ensino. 2015. 246 f. Dissertação (Mestrado em Língua e Literatura Francesa) - Faculdade de Filosofia, Letras e Ciências Humanas, Universidade de São Paulo, São Paulo, 2015.

ODDONE, I.; REY,A.; BRIANTE, G. Redécouvrir l'expérience ouvrière: vers une autre psychologie du travail. Paris: Editions Sociales, 1981.

SAUJAT, F. O trabalho do professor nas pesquisas em educação: um panorama. In: MACHADO, A. R. (org.). O ensino como trabalho: uma abordagem discursiva. Londrina: Eduel, 2004. p. 3-34.

SAUJAT, F. Quand un professeur des écoles débutant instruit son "sosie" de son expérience... Ou de l'intérêt d'une "méthode indirecte" dans l'analyse de l'activité enseignante. Les dossiers des sciences de l'éducation, Toulouse, n. 7, p. 107-117, 2002.

SAUJAT, F. Travail, formation et développement des professionnels de l'éducation: voies de recherche en sciences de l'éducation. Habilitation à Diriger des Recherches. Marseille: Université de Provence, 2010.

SAUSSEZ, F.; YVON, F. Problématiser l'usage de la co-analyse de l'activité en formation initiale à l'enseignement. In: PAQUAY, L. (org.). Travail réel des enseignants et formation. Quelle référence au travail des enseignants dans les objectifs, les dispositifs et les pratiques? Perspectives en éducation et formation. Louvain-la-Neuve: De Boeck Supérieur, 2014.

SCHNEUWLY, B. Vygotsky, l'école et l'écriture. Genève: Université de Genève, Faculté de Psychologie et des Sciences de l'Éducation, 2008.

SCHÖN, D. Formar professores como profissionais reflexivos. In: NÓVOA, A. (org.). Os professores e a sua formação. 2. ed. Lisboa: Publicações D. Quixote, 1995. p. 77-91.

SCHÖN, D. Educando o profissional reflexivo: um novo design para o ensino e aprendizagem. Tradução Roberto Cataldo Costa. Porto Alegre: Artes Médicas Sul, 2000.

SOARES, F. Aprendizagem do trabalho de ensinar pelo professor iniciante. 2016. $225 \mathrm{f}$. Dissertação (Mestrado em Língua e Literatura Francesa) - Faculdade de Filosofia, Letras e Ciências Humanas, Universidade de São Paulo, São Paulo, 2016.

SOUZA-E-SILVA, M. C.; FAÏTA, D. (org.). Linguagem como trabalho: construção de objetos de análise no Brasil e na França. São Paulo: Cortez, 2002.

VYGOTSKI, L. Pensée et langage. Paris: La Dispute, 1997. (Edição original: 1934). VIGOTSKI, L. S. A consciência como problema da psicologia do comportamento (Edição original: 1925). In: VIGOTSKI, L. S. Teoria e método em psicologia. 3. ed. São Paulo: Martins Fontes, 2004.

YVON, F.; SAUSSEZ, F. Analyser l'activité enseignante: des outils méthodologiques et théoriques pour l'intervention et la formation. Québec: Les Presses de l'Université Laval, 2010.

ZEICHNER, K. M. A formação reflexiva de professores: idéias e práticas. Lisboa: Educa, 1993. 
